\title{
Nuevas tecnologías y política
}

\section{Bermúdez, Emilia*}

\section{Resumen}

El presente artículo trata sobre los cambios que están sucediendo en la función de la política a partir del impacto de las nuevas tecnologías en la dimensión social temporal y en la creación de un mundo virtual; del desplazamiento de la razón política por la razón técnica y del cambio en las relaciones de poder. Se finaliza con una reflexión sobre la necesidad de repensar la politica en un espacio de creciente complejidad de la realidad real $y$ de la realidad virtual.

Palabras clave: Nuevas tecnologias, transformaciones, mundo virtual, política.

Recibido: 99-07-01. Aceptado: 99-11-17

* Investigadora del Centro de Estudios Sociológicos y Antropológicos de La Universidad del Zulia. E-Mail: ebh4654@iamnet.com. Telt.-Fax: (58-61) 432893. 


\section{New Technologies and Policy}

\section{Abstract}

This article deals with the changes that are occurring in political functions due to the impact of new technologies in the temporal, social dimension, and the creation of the virtual world, due to the displacement of political reasoning by technical reasoning, and because of changes in power relations. It concludes with a reflection as to the need to re-think politics in the framework of the growing complexity of both real and virtual realities.

Key words: New technologies, transformations, the virtual world, politics.

\section{Introducción}

No existen dudas que las nuevas tecnologias han provocado a lo largo de este siglo una alteración en todos las ordenes de la vida Societal. Ha impactado todas las formas de organización y relaciones humanas y las estructuras simbólicas que las han soportado.

El desarrollo de las fuerzas productivas que ha implicado el hecho tecnológico y la rapidez con la que ha permitido globalizar el mundo, trastocó y continua cambiando las relaciones económicas y laborales. Pero no es nuestro propósito referirnos a éste ámbito de las relaciones productivas el cual no es nuestra especialidad y que, por lo demás, ha sido trabajado con gran agudeza por distintos autores y recientemente analizado de una manera pedagógicamente admirable por Manuel Castell en el Vol. I de su obra titulada La Era de la Información, (1998). Nuestro propósito es reflexionar sobre otros aspectos relativos al impacto de las nuevas tecnologias en la política, en las formas de racionalidad y estructu- ras de sentido que emergen con la revolución tecnológica que estamos viviendo.

Este artículo se refiere en primer lugar, a los cambios que están sucediendo en la política a partir del descentramiento de la idea de tiempo, espacio, historia y futuro, producto de la velocidad que imprimen las nuevas tecnologias en especial, las relativas a la comunicación e informática y que hemos subtitulado Política y Mundo Virtual. En segundo lugar, se aportan algunas ideas para la discusión sobre el predominio de una racionalidad técnica y el desplazamiento de la racionalidad política; hecho que a nuestro juicio incide notablemente en el surgimiento de una nueva estructura de sentida que afecta el quehacer de la politica. En tercer lugar, plantea algunas nociones sobre el cambio que supone el hecho tecnológico en las relaciones de poder $y$, por último, dejamos expresadas varias de nuestras percepciones sobre el desafio que significa repensar la política desde una perspectiva distinta a la óptica con que hasta ahora la hemos mirado, lo que supone asumir los cambios 
que tiene para la política ésta nueva era de la información.

\section{Política y mundo virtual}

Desde que el hombre logró utilizar los movimientos del sol y la luna para establecer unidades de tiempo, éste se convirtió en el eje alrededor del cual los seres humanos organizaron sus actividades y relaciones, asi como buena parte de sus creencias, ritos, mitos y la orientación de su vida en general.

La aparición del reloj en la era moderna consolidó, como lo expresa Castell (1998:466), citando a Giddens, "el dominio del tiempo reloj sobre el espacio y la sociedad". El tiempo, además, se creó con una imagen lineal que dió forma secuencial a los acontecimientos e implantó una representación del movimiento de la historia y el futuro igual a la manera pausada como se mueven las manillas del reloj.

De ese modo, se edifica una lógica temporal en donde la historia determina al futuro $y$, por lo tanto, los procesos eran momentos que ameritaban tiempo para producirse y sedimentarse. Sobre esa lógica temporal, la política concibió la arquitectura de las grandes utopias y de los proyectos de cambios societales. Eran proyectos cargados de tiempo futuro lo que le permitia, a la política, cumplir su función de ordenadora del sentido social, minimizar la incertidumbre y proveer las certezas.

La rapidez que la velocidad de las nuevas tecnologías imponen al cambio, transforman la noción de tiempo al perturbar el orden secuencial de los fenómenos y nos ha sacado como diría Baudrillard
(1997:9) "de la esfera de lo real y de la historia". Es una aceleración del tiempo que no permite que nada se afirme. Es como sostiene Lechner respecto a la posmodernidad, "tiempo sin horizonte", en donde "los acontecimientos no logran cristalizarse en una "duración", es decir, un periodo estructurado de pasado presente y futuro" (Lechner, 1987: 259-260), porque las prácticas sociales ya no tienen el tiempo requerido para adquirir sentido (Lechner, 1990: 62) y los proyectos de futuro no pueden apoyarse en el pasado, imposibilitando la creación de una conciencia histórica que provea los criterios para anticipar el mañana. Debido a los drásticos cambios sociales ya no se cuenta con aquellas experiencias históricas que nos sivan de referente fijo. Situación que provoca la ausencia de un horizonte simbólicamente significativo y la imprevisibilidad del futuro. (Ibid, 64-66).

El mundo deviene en una fragmentación, en el cual, las continuidades temporales con las que estabamos acostumbrados a seleccionar y ordenar los distintos aspectos de la vida desaparecen. (Lechner, 1987: 261). "Las mediaciones que ejercen los medios tecnológicos fabrican un mundo de vida que es siempre presente" (Bermúdez y Martínez, 1999: 6). Paul Virilio (1997:27) lo denomina el "tiempo luz", en donde la duración intensiva del instante real" predomina sobre la duración del tiempo extensivo y relativamente controlable de la historia, es decir el largo plazo que engloba pasado, presente y futuro.

La política se desenvuelve en un tiempo presente; en un presente fugaz en el cual no es posible consolidar referentes, dando lugar a la pérdida de un hori- 
zonte de futuro colectivo. Sin referentes colectivos, el otro, como expresa Baudrillard (1997) "existe por si mismo". El sujeto se aleja del espacio exterior como referencia y es capaz de desdoblar su existencia en múltiples espacios y tiempos y múltiples sí mismos, al interconectarse y existir en el espacio y el tiempo virtual. "Las experiencias colectivas en épocas y espacios del territorio nacional van cediendo paso al territorio virtual en el cual predomina la desagregación de un nosotros, para la reconfiguración del otro nosotros que habita, siente, se comunica e interactúa en el ciber espacio". (Bermúdez y Martínez, 1999: 54).

Así, a partir de las tecnologías se estructuran nuevas formas de sociabilidad en el espacio virtual que potencian al mismo tiempo la fragmentación de un mundo real que dificulta a la política la construcción de un horizonte de sentido. Se forma un mundo en que la pluralización de los sujetos se convierte en la característica sobresaliente (Welsh, 1997: 43).

El futuro se disuelve en un continuum sin historia en el que han desaparecido las grandes utopías sociales y en el que tampoco existe la idea de nación como ámbito espacio - temporal en el que se evoca la tradición, la patria y la historia; elementos básicos para crear identidades nacionales.

La construcción del sentido social se desplaza del espacio de la política, hacia un mundo que no tiene historia, "sólo hay pantalla y red" (Baudillard, 1994: 9); ó a un mundo en donde dejamos de ser sujetos o actores para convertirnos en espectadores de un escenario en donde la "historia está en directo". (Dayan y Katz, 1995). Son formas de producción de un nuevo universo simbólico en donde se resemantizan los símbolos de las viejas utopías mediante un proceso de descontextualización que las convierte en imágenes sin historia; en mercancías. Además, en el caso de los medios de comunicación e información nos lanzan a un mundo de ciencia-ficción que escamotea y disuelve el presente. (Martín-Barbero, 1997: 200).

Esos mismos medios de comunicación son los que por otra parte, desplazan hoy a los actores políticos tradicionales del papel hegemónico en la construcción de lo político. En algunos países, en especial en América Latina, intervienen cada vez más, en la legitimación de los actores, en establecer los temas del debate político e inclusive en la orientación de los acontecimientos políticos.

Por supuesto que en todas las sociedades modernas los medio de comunicación ejercen funciones políticas (Sánchez; 1997) y esto ha llevado a subrayar el carácter conflictivo entre el poder político y los medios. Pero, en la actualidad el clima creado por el desencanto con la política, la caída de los grandes relatos y el surgimiento de la razón posmoderna, han creado las condiciones para que la política, parafraseando a Lechner (1996), "ya no es lo que fue". El desencanto con la política ha hecho que las nuevas tecnologías, y en especial los medios audiovisuales, hayan pasado a ser un escenario fundamental de la construcción de la vida política y "mediadores sociales y tecnológicos de la construcción política actual" (Canelón; 1996: 15). 
No se trata entonces de una tecnofobia que achaca todos los males a la tecnología, sino de llamar la atención sobre nuevos procesos que exigen repensar el papel que la razón ilustrada concedió a la política como la arquitecta del orden social y la creación del sentido de comunidad.

De hecho estamos conscientes que la mundialización de las comunicaciones ha permitido nuevos modos de socialización y participación ciudadana (Sánchez; 1997); y es eso precisamente lo que nos lleva a no tener una visión apocaliptica de estos procesos. En la "sociedad real" se están creando espacios para la confrontación de ideas y para la lucha política, tal y como ha ocurrido con el movimiento de la guerrilla zapatista de Chiapas en México, que han conquistado audiencia no sólo en Internet, sino a través de la televisión, dejándose entrevistar y dando a conocer sus posiciones políticas, filosóficas y culturales. Lo mismo ha ocurrido con otros movimientos y acontecimientos políticos y sociales que han encontrado en el espacio virtual un novedoso terreno de lucha, a partir de la difusión y la confrontación ideológica en el ciberespacio.

De lo que se trata es entonces de entender un movimiento contradictorio que no expresa otra cosa que la complejidad de un mundo en donde la contradicción no es necesariamente antagónica. Las nuevas sociabilidades crean otras realidades que urgen de la política en el sentido que le atribuye Savater (1992: 41) "el conjunto de las razones para obedecer y las razones para sublevarse". La globalización impulsada por las nuevas tecnologías de información y comunica- ción, dan paso al mismo tiempo a un fraccionamiento social que solo la política puede recomponer mediante su capacidad para garantizar lo colectivo a partir del respeto a la pluralidad de los distintos movimientos que se han creado en el espacio local del mundo real y de la creación de nuevos imaginarios a partir de la realidad virtual. La política necesita acercarse a la comprensión de esos imaginarios y de las nuevas formas de sociabilidad de las prácticas tecnológicas, entendidas estas últimas como "relaciones objetuales que involucran relaciones intersubjetivadas mediadas técnicamente" (Abril, 1998: 62). Tal vez el camino sea, contradictoriamente, una vuelta al mundo inmediato de referencias y relaciones cotidianas que nos ayuden a comprender $y$ recomponer al sujeto fractal de nos habla Baudrillard (1994: 34).

\section{Razón técnica y razón política}

La revolución industrial y el surgimiento de las sociedades modernas marcan el tiempo de la racionalidad técnica cartesiana sobre la moral religiosa mitica y la metafísica. Sin embargo, en los últimos tiempos, el descontento con la política ha abierto paso para que la razón técnica ocupe el espacio de orientadora del orden social que tiene la política.

Desde la década de los sesenta se viene cuestionando y denunciando las formas de dominio político que está detrás de la idea de tiempo de la razón técnica. Marcuse llamó la atención sobre el ocultamiento de la explotación detrás de la tecnología y las formas distintas que asume la legitimación en la sociedad ca- 
pitalista. (Habermas, 1994). Pero, la innovación tecnológica no significa el sometimiento inmediato a las exigencias de la racionalidad tecnológica, lo que ocurre con el desarrollo tecnológico es que el origen de los cambios no está en la técnica misma, esto es parte de un proceso mucho más complejo que obedece a la lógica de la estructura racional de medios con respecto a fines (Martín-Barbero; 1997:31). Estructura que ha dado lugar al desplazamiento de un conjunto de valores y al surgimiento de una ideología tecnocrática que "se distingue de las antiguas en que los criterios de justificación los disocia de la organización de la convivencia, esto es, de la regulación normativa de las interacciones, y en este sentido los despolitiza; en lugar de eso los vincula a las funciones del sistema de acción racional con respecto a fines que se supone en cada caso". (Habermas, 1994:98).

El desplazamiento de la razón política por la razón instrumental encuentra terreno abonado en el proceso de despolitización de la sociedad producto de la obsolescencia en las formas de hacer política, de las funciones de la misma, en la resistencia al cambio de los mecanismos tradicionales de legitimación, la caída de las grandes utopias y la imposibilidad de producir un horizonte de futuro compartido. Es lo que N. Lechner (1990) ha llamado el "desencanto con la politica". En este contexto, la racionalidad instrumental y su profesionalización pasan a predominar en la concepción y la acción política misma.

Se trata de una tendencia que se inicia a partir del mismo momento en que la actividad estatal fue orientada a garantizar la estabilidad del sistema económi- co. La política pasa a tener como objetivo la prevención de las disfuncionalidades y riesgos que amenazan el sistema, asumiendo la resolución de cuestiones técnicas. (Habermas, 1994: 84). El desarrollo de una orientación y dirección de la sociedad basada en el progreso científico técnico desplaza a la política como orientadora del orden social y ésta pasa a satisfacer necesidades funcionales. " $Y$ cuando esta apariencia se ha impuesto con eficacia, entonces el recurso propagandístico del papel de la ciencia y la técnica puede explicar y legitimar por qué en las sociedades modernas ha perdido sus funciones una formación democrática de la voluntad política en relación con las cuestiones prácticas y puede ser sustituido por decisiones plesbicitarias relativas a los equipos alternativos de administradores". (Habermas, 1994: 88). El desarrollo de las nuevas tecnologlas de información y comunicación vendrán a acelerar la muerte de la razón política.

La solución a los problemas generales de la humanidad se le asignan cada vez más a los poseedores de la racionalidad tecnológica. Se imponen en la gestión pública los modelos tecnocráticos y con ello la sustitución de los valores de la razón política que inspiró el iluminismo: "igualdad", "libertad", "fraterni-

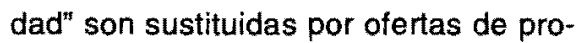
ductividad, eficacia, rendimiento, calidad y eficiencia en la gestión pública, presentada como la única manera de resolver los problemas de las mayorias desasistidas, en especial, en los paises con grandes problemas sociales y económicos, como son por ejemplo, los países de América Latina. El Estado orientado por la búsqueda de la equidad so- 
cial, es suplantado por el Estado eficiente. Eficiencia que se garantiza con el uso de recursos tecnológicos, principalmente tecnologías avanzadas de información y con la intervención de técnicos especialistas. Especialistas que deciden la dirección del orden social en función de los parámetros que establecen los valores del mercado, lo que significa un reordenamiento simbólico que desplaza a las doctrinas e ideologias políticas como articuladoras del sentido social.

\section{Nuevas tecnologías $y$ relaciones de poder}

Los ordenadores a diferencia de otro tipo de máquinas que tienen como caracteristica prolongar la capacidad física del hombre, tienen como particularidad que ayudan a proyectar el pensamiento del hombre ( $M$. Sulbarán, 1990). Lo que Mc Luhan (1991: 99) pensó acerca de la mente proyectada en el espacio virtual ya no es una quimera, es una realidad; que significa, no sólo la suplantación del cerebro humano por el hombre electrónico, sino, la multiplicación de las capacidades mentales de muchos individuos interconectados en el ciber espacio y que ha sido llamada la "'inteligencia conectada" (D. de Kerckhove, 1998). Lo que surgió como una necesidad de información ha logrado una extensión tal que ha pasado a dominar todos los ámbitos sociales e instaura nuevas formas de sociabilidad que implican el traslado de la fuente del poder hacia la posición de la Ciencia y la Tecnología.

La tecnología es ciertamente una fuerza estructurada pero el mismo tiempo estructurante. En este sentido la lógica voraz que el capitalismo ha impuesto en su incesante carrera de producción de mercancías y consumidores tecnológicos ha dado paso a nuevas relaciones de poder, basadas en la posición del conocimiento y la tecnología. La capacidad para dirigir el futuro del mundo reside en el monopolio del capital científico tecnológico de unos y la debilidad y desigualdad de otros en desventaja respecto al ritmo de la innovación tecnológica; tanto en la que puede garantizar la vida y el bienestar como en la que puede asegurar la derrota y la muerte.

Como lo plantea Orozco citando a Fiske " el acceso al conocimiento, su posición y circulación en las sociedades contemporáneas entraña poder" (1997: 23) y el tránsito hacia el bloque del poder esta delimitado, entre otras cosas, por la capacidad de ser excluidos a ser poseedores del "pasword" del acceso a la información, sus fuentes y medios de circulación" (lbid, 25). De esa forma, sostiene el autor que venimos citando, ".. la cada vez más drástica división entre los que no tienen y los que tienen, en buena parte es un resultante de sus posibilidades de definir al desarrollo de los medios y de ser sujetos de la información circundante" (Ibid, 26).

En este contexto de creciente protagonismo de las tecnologías de la información, ellas son fuentes cruciales del dominio y del cambio en nuestra sociedad (Castell, 1998: 505). Proporcionan las bases para la sustentación de nuevas relaciones de poder político, económico, social y cultural. "La inclusión / exclusión de las redes y la arquitectura de las relaciones entre sí, facilitadas por las tecnologias de información que operan a la velo- 
cidad de la luz, configuran los procesos y funciones dominantes en nuestras sociedades" (lbid, 506). Por supuesto no puede olvidarse que la inclusión / exclusión de los sistemas de información es una resultante de las desigualdades económicas, tanto, entre unos paises y otros, como al interior de cada una de las sociedades, pero lo cierto es que la tecnología misma pasa a ser la fuerza productiva fundamental y al mismo tiempo la mercancía de más alto valor en el mercado.

Por otra parte, a partir del acceso a la tecnología de información se inaugura una nueva diferenciación y exclusión social "los conectados y los desconectados" que en un mundo dominado por el conocimiento significa la hegemonía por una parte, de quienes tienen la información para imponer estructuras simbólicas y por otra parte, la exclusión en la dirección de los procesos económicos, sociales, políticos, cientificos y culturales a quienes no han podido, al menos, tener acceso al conocimiento.

Esas formas de estructuras de poder que se crean a partir de las tecnologias de información, también las encontramos en otros espacios como el de la biotecnologia, que representa el posible dominio del mundo a través de la biogenética y su consecuente impacto sobre el cambio en la estructura de valores actuales y la instauración de nueva formas de sociabilidad basada en relaciones asexuales que significan incluso la transformación a la forma y el sentido que el hombre ha dado a su propia reproducción y existencia.

Como lo expresa Habermas "La especie humana se ve asi desafiada por las consecuencias socioculturales no planificadas del progreso técnico mismo, no sólo a conjurar como ya lo ha hecho su destino social, sino también, a aprender a dominarlo. Pero a este desafío de la técnica no podemos hacerle frente únicamente con la técnica. Lo que hay que hacer, más bien, es poner en marcha una dimensión política eficaz que logre poner en relación de forma racionalmente vinculante el potencial social del saber y el poder técnico con nuestro saber y querer práctico" (Habermas, 1994: 128-129). Es necesario ser capaces de recuperar el sentido mismo de la política y de la ciencia al servicio del hombre por parte de los actores políticos. Sólo la "formación política de una voluntad colectiva" (Ibid, 1994: 129) y la revalorización de lo humano garantizan el desarrollo de la humanidad y, esta es tarea que no puede dejarse a las tecnócratas para quienes siempre privará la rentabilidad económica, ni a las fuerzas ciegas de la ciencia, porque el propio campo científico está atravesado por relaciones de poder sustentadas en el monopolio del conocimiento y la capacidad de imponer sentido a partir de la consagración del prestigio que le da el saber y determinado por los intereses sociales en juego.

\section{Repensar la política}

Las transformaciones tan profundas que vivimos en este momento tienen como lo expresa Castañares (1988: 5) un nombre. "Era de la información". Se trata de la aparición de un nuevo lenguaje, el digital, que rescribe y combina cualquier tipo de información y su transmisión a la velocidad de la luz a cualquier lugar de la tierra (Ibid, 16). Es una era en la que infor- 
mación y conocimiento son sinónimos. Es la era del ciberespacio y la Cibercultura sugiriendo nuevas formas de apropiación del sentido que rompen con la visión de totalidad como sistema armónico como sujeción a la unidad, a la que nuestro pensamiento estaba acostumbrado.

Se trata de transformaciones que exigen asumir la multiplicidad de dimensiones que acompañan a los nuevos fenómenos que conviven en un mismo espacio aparentando ser contradictorios, cuando en realidad, son parte de un mismo movimiento que unifica en un espacio y diversifica en otros. Movimientos que desafían la lógica mental con la que nos acostumbramos a ver lo real natural o social, siempre pensando en la idea de la búsqueda del equilibrio a través de elementos que crean armonía al complementarse.

Pensar la política en una perspectiva distinta es perentorio, porque nos ayuda a comprender la necesidad de plantearse y reconocer los cambios a partir de estas nuevas realidades y a asumir la existencia del antagonismo (que pareciera generarse entre diferentes realidades) entre lo real y lo virtual, lo político y el hecho tecnológico sin tomar posiciones fundamentalistas o tecnofóbicas.

Para ello es necesario entender que el tejido de la realidad política es juego múltiple de interacciones y retroacciones (Morín, 1997: 32) y es imprescindible que la política se fundamente en los principios lógicos y translógico que permitan la comunicación entre el conocimiento y la política.

Se trata de una comunicación que retome el sentido ético de la humanización, la cual sólo puede estar sustentada en la refundación misma del sentido de una política que tenga como principio rector la revalorización misma del conflicto y la diferencialidad. Una política que ya no puede plantearse acabar con la incertidumbre porque la velocidad del cambio no lo permite y la caída de los grandes relatos tampoco, pero que puede ayudar a revalorizar otros referentes en el espacio cotidiano y en la misma realidad virtual. Creemos que "la política es la única mediación posible entre valores y técnicas entre sistema económico y vida privada" (Touraine, 1998: 69). No militamos ni en el pesimismo que anula al sujeto, ni en el postmodemismo que lo hace sólo fractal. Creemos que el hombre es por naturaleza gregario y tiende a su conservación; que necesita de otros hombres para construir su humanidad y que por ello la política nunca desaparecerá.

\section{Bibliografía citada}

Abril, Gonzalo (1988), "Sujeto, Interfaces, Texturas" en Revista de Occidente, No 206. Edita Fundación José Ortega y Gasset, Barcelona, España. Junio.

Baudrillard, Jean (1994). El otro por sí mismo. Editorial Anagrama. Segunda Edición, Barcelona, España.

Baudrillard, Jean (1997). La llusión del Fin, Editorial Anagrama, Tercera Edición, Barcelona, España.

Bermúdez, Emilia y Martínez, Gildardo (1999). "Identidades colectivas en el Ciberespacio", en Revista Comunicación No. 105, 1er. Trimestre, Centro Gumilia, Caracas, Venezuela.

Castañares, Wenceslao (1988). "Pensar en fufuro" en Revista de Occidente, № 206. Edita Fundación José Ortega y Gasset, Barcelona, España, Junio. 
Castell, Manuel (1998). "La Era de la Información". Economía Sociedad y Cultura. Vol. I y Vol. II. Segunda Reimpresión, Madrid, España.

Canelón, Agrivalca (1996). "Los Medios de Comunicación Social en Venezuela, Actores Sociopoliticos" en Revista Comunicación, Estudios Venezolanos de Comunicación N N 96, Cuarto Trimestre. Centro Gumilla, Caracas.

Dayan, Daniel y Elihu, Katz (1995). La Historia en Directo. Ediciones Gustavo Gili, S.A. México.

De Kerckhove, Derrick (1988). "Inteligencia Conectada y Mente Colectivo" en Revista de Occidente, $N^{\circ}$ 206. Edita Fundación José Ortega $Y$ Gasset, Barcelona, España, Junio.

Habermas, Jürgen (1994). Ciencia y Técnica como Ideología. Editorial Tecnos, Tercera Edición, reimpreso, España.

Lechner, Nobert (1987). Cultura Política y Democratización, Clascso, Biblioteca de Ciencias Sociales, Chile.

Lechner, Nobert(1990). Los Patios Interiores de la Democracia, Fondo de Cultura Económica, Segunda Edición, Chile.

Lechner, Nobert (1996). "La Politica ya no es to que fue" en Revista Nueva Sociedad $N=144$, Nueva Sociedad, Cara cas, Julio-Agosto.

Martín Barbero, Jesús (1997). De los Medios

a las Mediaciones. "Comunicación, Cultura y Hegemonia". Ediciones Gustavo Gili. México, cuarta edición.

Martín Barbero, Jesús (1997). "Globolización Comunicacional y Decestramiento Cultural" en Revista Diálogos de la Comunicación. Número 41. Santa Fé de Bogotá, Colombia.

Mc Luhan, Marshall (1991). La Aldea Global, Editorial Gedisa, Primera Edición, México, 1991.
Morin, Edgar (1997). Introducción al pensamiento, Complejo Editorial Gedisa, Tercera reimpresión, Barcelona, España.

Orozco, Guillermo (1997). "Más mediación y audienciación". Mactotendencia en la Sociedad Latinoamericana de fin de Milenio", en Revista Comunicación № 100. Estudios Venezolanos de Comunicación. Centro Gumila, Caracas, Venezuela, Cuarto Trimestre, 1997.

Sánchez Noriega, José L. (1997), Critica de la Seducción Mediática. Editorial Tecnos, Madrid, España.

Sulbarán, Manuel C. (1990). "Cultura y Socie. dad (Ensayo)". Trabajo de Ascenso para optar a la Categoría de Profesor Titular. Universidad del Zulia, Facultad de Ciencias Económicas y Socia. les. Escuela de Sociología. Maracalbo. (Mimeografiado).

Savater, Fernando (1992). Política para Amador, Editorial Ariel, Colombia.

Savater, Fernando (1998). "La Humanidad en Cuestión" en VATTIMO, Gianni (comp). La Secularización de la FiIosofia, Editorial Gedisa, Barcelona, España.

Touraine, Alain (1998). "El Concepto de Desarrollo "Revisted" en SADER, Emir (editor). Democracia sin exclusiones ni excluidos. Nueva Sociedad, Caracas.

Virilio, Paúl (1997). La velocidad de liberación, Ediciones Manantial, Buenos Aires, Argentina.

Welsh, Wolfang (1997). "Topoi de la posmodernidad". En Fischer, M. R., Retzery Schweitzer (Compiladores). El Final de los grandes Proyectos, Editorial Gedisa, Barcelona, España. 